\title{
Attitudes of parents toward the return of targeted and incidental genomic research findings in children
}

\author{
Conrad V. Fernandez, MD1', Eric Bouffet, $\mathrm{MD}^{2}$, David Malkin, MD², Nada Jabado, MD, PhD², \\ Colleen O'Connell, $\mathrm{PhD}^{4}$, Denise Avard, PhD5, Bartha M. Knoppers, PhD, LLM ${ }^{5}$, \\ Meghan Ferguson, MSc ${ }^{6}$, Kym M. Boycott, MD, PhD7, Poul H. Sorensen MD, PhD ${ }^{8,9}$, \\ Andrew C. Orr, MD ${ }^{10}$, Johane M. Robitaille, MD ${ }^{10}$ and Christopher R. McMaster, PhD ${ }^{11}$
}

Purpose: We describe parental attitudes toward the return of targeted and incidental genomic research results in the setting of highrisk pediatric cancer and inherited childhood diseases.

Methods: A validated 36-item questionnaire was mailed to participants in three large-scale genome research consortia examining attitudes toward receipt of genomic research results and the influence of certainty, severity, and onset of the condition, in addition to responsibilities to extended family and provision of results even after death of the proband.

Results: Of the 563 participants who were sent questionnaires, 362 (64\%) responded. Most of them stated a positive right to receive results related to the target condition (97\%) or to incidental findings (86\%); no difference was found in results between participants with cancer and those with orphan diseases. Furthermore, 92\% indicated that genomic research for childhood-onset conditions should occur. The majority wanted incidental results predicting susceptibility even to untreatable fatal conditions (83\%), to multiple conditions (87\%), or to those with uncertain impact (70\%). Most felt sibling genomic results showing serious conditions, whether treatable (93\%) or not (88\%), and/or results discovered after death of the proband should be shared with family (74\%).

Conclusion: Many parents of children in pediatric genomic research indicated a strong desire to receive a broader range of results than is described in consensus recommendations. Clear delineation of what will be offered should be established at the time of consent.

Genet Med advance online publication 16 January 2014

Key Words: genomics; incidental findings; participants; next-generation sequencing

\section{INTRODUCTION}

The power of genomic research techniques is increasingly incorporated into the exploration of many conditions, including, more recently, the genomic profiles of rare (orphan) conditions and pediatric cancers. Consensus guidelines typically advise sharing target and incidental results that are analytically valid, actionable, and clinically significant. ${ }^{1-3}$ Many expert recommendations are rooted in adult perspectives and attempt to weigh potential benefits and harms to the participants, as well as the feasibility of such sharing. ${ }^{4-6}$ Specific expert opinion on the implications of genomic research discovery in a pediatric context is emerging. ${ }^{7-9}$ Adult participants in research strongly voice an interest in being offered genetic research results, including those incidental to the primary aims. ${ }^{10,11}$ The empirical evidence to understand parental attitudes toward the sharing of genomic research results derived from research with children has just begun to be explored. ${ }^{12-15}$ There is also considerable debate about the extent to which family members should be informed of potentially relevant genomic information gathered in a pediatric context. ${ }^{16,17}$

We used the rich resource of three Canadian consortia ${ }^{18-20}$ that primarily study children to examine parental attitudes toward the return of genomic results. We were able to leverage the nature of the study populations-patients with pediatric cancers and individuals with inherited orphan diseases-to examine whether the context of the illness influences subsequent attitudes toward the return of genomic research results. It has been suggested that these two populations may view their obligations to extended family members differently, given the inherent broader familial impact of inherited conditions versus that of typically isolated pediatric cancers. ${ }^{21,22}$ We explore themes focused on parental attitudes toward (i) sharing of target and incidental findings discovered in the course of pediatric genomic research; (ii) responsibilities toward family members; (iii) acceptability of children participating in genomic research;

\footnotetext{
${ }^{1}$ Department of Pediatrics, IWK Health Centre and Dalhousie University, Halifax, Nova Scotia, Canada; ${ }^{2}$ Division of Pediatric Hematology/Oncology, Department of Pediatrics, The Hospital for Sick Children, University of Toronto, Toronto, Ontario, Canada; ${ }^{3}$ Department of Pediatrics, McGill University/McGill University Health Center, Montreal, Quebec, Canada; ${ }^{4}$ Perinatal Epidemiology Research Unit, IWK Health Centre, Halifax, Nova Scotia, Canada; ${ }^{5}$ Centre of Genomics and Policy, Department of Human Genetics, Faculty of Medicine, McGill University, Montreal, Quebec, Canada; ${ }^{6}$ Maritime Medical Genetics Service, IWK Health Centre, Halifax, Nova Scotia, Canada; ${ }^{7}$ Children's Hospital of Eastern Ontario Research Institute, University of Ottawa, Ottawa, Ontario, Canada; ${ }^{8}$ Department of Molecular Oncology, BC Cancer Research Centre, University of British Columbia, Vancouver, British Columbia, Canada; ${ }^{9}$ Department of Pathology, University of British Columbia, Vancouver, British Columbia, Canada; ${ }^{10}$ Department of Ophthalmology and Visual Sciences, Dalhousie University, Halifax, Nova Scotia, Canada; ${ }^{11}$ Department of Pharmacology, Dalhousie University, Halifax, Nova Scotia, Canada. Correspondence: Conrad V. Fernandez (conrad.fernandez@iwk.nshealth.ca)
} 


\section{ORIGINAL RESEARCH ARTICLE}

and (iv) opinions about the process and experience of sharing genomic results. ${ }^{2,23,24}$ We believe our findings will help researchers across disciplines as they grapple with the inevitability of uncovering genomic research findings potentially relevant to the child and the extended family.

\section{MATERIALS AND METHODS}

The study was approved by the IWK Health Centre Research Ethics Board (REB), Halifax, Nova Scotia; the Children's Hospital of Eastern Ontario REB, Ottawa, Ontario; the Hospital for Sick Children REB, Toronto, Ontario; and the Montreal Children's Hospital REB, Montreal, Quebec. Participants were informed that return of the questionnaire implied consent, except in Quebec, where written consent is required by law.

\section{Setting and participants}

All participants were contacted through one of three genomic research consortia-The Canadian Pediatric Cancer Genome Consortium (CPCGC), The Finding of Rare Disease Genes in Canada Consortium (FORGE), and the Orphan Diseases: Identifying Genes and Novel Therapeutics to Enhance Treatment (IGNITE) project. The primary objective of the $\mathrm{CPCGC}^{19}$ is to gain insight into novel genomic causes of pediatric cancers with poor prognosis, evolution of genomic changes in metastatic or recurrent disease, and identification of targets for therapeutic intervention. All samples used within the CPCGC were either anonymized or archived samples obtained without consent for return of results; thus, for a surrogate population for our survey, we contacted parents of patients with a pediatric cancer diagnosis from two participating CPCGC institutions. All of these patients had been diagnosed within 2 years of the survey.

The main objective of FORGE ${ }^{18}$ is the identification of the genetic causes of rare childhood-onset diseases in individuals and families. Patients (of pediatric or adult age) as well as unaffected family members were recruited to FORGE primarily through medical geneticists if they met the definition of having a rare disease. ${ }^{25}$ The aims of IGNITE ${ }^{20}$ are similar to those of FORGE, with the addition of a major platform for drug discovery. IGNITE and FORGE were actively studying participants at the time of the survey, and the consortia consent process and forms indicated that participants might be approached with genomic results (both incidental and targeted) if significant health implications were uncovered. The types of conditions under study are shown in Supplementary File S1 online. All three consortia use next-generation genomic and bioinformatics strategies to interrogate the genome.

\section{Study questionnaire}

The questionnaire (see Supplementary File S2 online) included self-described demographics and the following themes based on a literature review, expert review, and a concurrent qualitative questionnaire being constructed for the FORGE consortium. These included: (i) the perceived right of parents to receive incidental or target results; (ii) the attitudes of parents toward the
FERNANDEZ et al | Participant attitudes toward targeted and incidental genomic findings

participation of children in genomic research; (iii) the sharing of genomic results with uncertain impact, results from siblings, or findings obtained after death of the proband; and (iv) the likelihood and preferred mode(s) of access by parents to study results. Definitions were included before each section of questions. We used the method of Dillman ${ }^{26}$ to create five-point Likert scale and open- and closed-ended questions. Formal content validity rating by individuals affected by rare genetic conditions $(n=5)$ was 0.87 for individual questions and the instrument overall. Cronbach's $\alpha$ reliability analyses (for questions 14-19) indicated significant internal consistency both within the items for each question (range: $0.583-0.794, P<0.001$ ) and within all items of those questions when considered as a group $(\alpha=0.815$, $P<0.001)$. Questions 9 and 13 showed a Cronbach's $\alpha$ of 0.662 and 0.871 , respectively, within each question $(P<0.001)$. The English-language questionnaire had 36 items, and pilot testing with five parents resulted in minor revisions. The participants took 20-25 min to complete the questionnaire. A French version was created by professional translation. All participants were offered a summary of the results.

\section{Study design}

Distribution occurred by the consortia participating sites (Halifax, St. John's, Montreal, Ottawa, Toronto, Winnipeg, and Vancouver, Canada). All participants fully registered in IGNITE and FORGE up to the time of the REB submission of the questionnaire were invited to participate. In the CPCGC, two recruitment strategies were used. In one hospital, consecutive patients from an internal database with high-risk pediatric brain tumors were contacted. In a second hospital, consecutive brain tumor patients were approached in an oncology clinic, and they provided written informed consent. A preannouncement was sent 1 week before the questionnaire was distributed by postal mail. Questionnaires were coded for tracking but had no other identifying information. The self-administered questionnaire was sent between July and November 2012 with a cover letter, incentive gift card, and a stamped return envelope. Two reminders were sent at 2 and 5 weeks to nonresponders. Participants could complete the questionnaires online, if they preferred. Questionnaires were returned by mail to the participant's local institution and sent to the IWK Health Centre for duplicate data entry.

\section{Statistical analysis}

Data were analyzed using SPSS version 14 (IBM, Somers, NY). The results from the three consortia were pooled, except where noted, and the calculated response percentages are based on the total number of responses to each question. We present the results from the questionnaire using descriptive statistics. Pearson's $\chi^{2}$ test, $t$-test, and the Mann-Whitney test, as appropriate, were conducted to assess the associations between demographic variables and specific respondent attitudes. We identified a priori all variables planned for univariate analysis. These variables included categorical (dichotomous) distributions of age, ethnicity, education, family income, level of comfort with medical language, and comfort with the Internet for 
health-related searches. The REB did not allow collection of data to analyze gender or attrition.

\section{RESULTS}

Response rates for the consortia were as follows: for IGNITE $(n=221 / 325,68 \%)$, for CPCGC $(n=86 / 155,55 \%)$, and for FORGE $(n=55 / 83,66 \%)$; overall 362/563 (64\%). Missing data rates were generally low, except for one question regarding the reliability of laboratories, for which the missing data rate was more than $50 \%$. Demographics for the respondents are shown in Table 1 . The majority described being very comfortable or comfortable with reading medical language $(n=220 / 349,63 \%)$ and using the Internet $(n=280 / 341,82 \%)$.

On Pearson $\chi^{2}$ analysis, respondents from the three consortia were not significantly different using categorical groupings as shown in Table 1, except as follows: FORGE respondents were proportionately younger than IGNITE respondents $(P=0.01)$, FORGE respondents were proportionately more highly educated than respondents from either of the other consortia $(P=$ 0.02), CPCGC respondents had a higher proportion of ethnic minorities $(P<0.01)$ than respondents from either of the other consortia, and IGNITE respondents were proportionately more likely to report a lower income $(P<0.01)$ and had less comfort with the Internet. One-quarter of the CPCGC respondents indicated that their child who had been affected with the condition under study had died $(n=20 ; 23.3 \%)$.

Table 1 Self-reported demographic characteristics of survey respondents from the IGNITE, CPCGC, and FORGE consortia

\begin{tabular}{|c|c|c|c|c|}
\hline & IGNITE & CPCGC & FORGE & Total $^{\mathrm{a}}$ \\
\hline Characteristic & $n(\%)$ & $n(\%)$ & $n(\%)$ & $n(\%)$ \\
\hline \multicolumn{5}{|l|}{ Age range } \\
\hline Less than 35 years & $23(11)$ & $11(13)$ & $13(24)$ & $47(13)$ \\
\hline $\begin{array}{l}\text { More than or } \\
\text { equal to } 35 \text { years }\end{array}$ & $190(89)$ & $72(87)$ & $42(76)$ & $304(87)$ \\
\hline \multicolumn{5}{|l|}{ Education } \\
\hline $\begin{array}{l}\text { High school (up to } \\
\text { grade 12) or less }\end{array}$ & $32(15)$ & $14(17)$ & $2(4)$ & $48(14)$ \\
\hline College/university & $178(85)$ & $69(83)$ & $53(96)$ & $300(86)$ \\
\hline \multicolumn{5}{|l|}{ Ethnicity } \\
\hline Caucasian (white) & 207 (94) & $57(66)$ & $48(87)$ & $312(86)$ \\
\hline $\begin{array}{l}\text { All other } \\
\text { ethnicities }\end{array}$ & $14(6)$ & $29(34)$ & $7(13)$ & $50(14)$ \\
\hline \multicolumn{5}{|l|}{ Annual family income } \\
\hline $\begin{array}{l}\text { Less than or equal } \\
\text { to } C d n \$ 50,000\end{array}$ & $82(52)$ & $17(22)$ & $9(21)$ & $108(39)$ \\
\hline $\begin{array}{l}\text { More than Cdn } \\
\$ 50,000\end{array}$ & $77(48)$ & $61(78)$ & $33(79)$ & $171(61)$ \\
\hline
\end{tabular}

Cdn, Canadian; CPCGC, Canadian Pediatric Cancer Genome Consortium; FORGE, Finding of Rare Genes Canada Consortium; IGNITE, Orphan Diseases: Identifying Genes and Novel Therapeutics to Enhance Treatment.

aNot all respondents replied to each question.

\section{Attitudes to the right and desire to receive genomic research results}

The majority indicated a belief that they had a strong $(n=90$, $28 \%)$ or very strong $(n=229,70 \%)$ right to receive the results of genomic research that were directly related to the condition under study. A slightly smaller majority also felt that they had a strong $(n=82,26 \%$ or very strong $(n=200,62 \%)$ right to receive genomic research results that were incidental to the main aims. Parents of children with cancer did not significantly differ in this regard from participants in IGNITE or FORGE. Respondent age, education, ethnicity, or comfort with medical language had no statistically significant influence on these attitudes as determined by Pearson $\chi^{2}$ analysis. Any reported experience in using the Internet to seek health information was associated with a higher likelihood of wishing to receive incidental results $\left(\chi^{2} P=0.02\right)$. If the researcher was uncertain about the health impact of the genomic finding, respondents felt that the results should be returned ( $n=137 / 322,42.5 \%)$ or that there should be a joint decision made between the researcher and the participant $(n=134 / 322,41.6 \%)$. Few were willing to delegate the task of determining what to do with uncertain results to the researcher alone $(n=18,5.6 \%)$ or to an independent expert committee $(n=25,7.8 \%)$. In the hypothetical situation in which such a committee had indeed been established, the majority of respondents wished to be informed that decisions were being made $(n=272,75.1 \%)$ and to be able to challenge a decision not to share results $(n=247,68.2 \%)$. The expressed right to challenge a decision not to share results was not associated with respondent age, education, income, comfort with use of the Internet, or comfort with medical language. However, respondents with a self-reported Caucasian background were more likely to wish to challenge such a decision (Pearson $\left.\chi^{2} P=0.007\right)$.

Participant attitudes for themselves and their child in the event that genomic research uncovered unexpected (incidental) findings are shown in Table 2. On $\chi^{2}$ analysis, there was no difference $(P=0.32)$ between respondents whose child had cancer versus those whose child had orphan diseases regarding whether or not they would want results that were associated with early death and no effective treatment. More than half indicated that they would want the result no matter how uncertain the effects on health $(n=223 / 318$, $70.1 \%)$. In addition, most felt that there should be no maximum number of incidental genomic findings returned, if they had potential relevance to the person's health ( $n=276 / 316$, 87.3\%). We asked respondents to indicate the reasons they felt were important in offering genomic results (Table 3) and to describe what issues parents should consider before accepting an offer (Table 4).

\section{Attitudes to the participation of children in genomic research and the return of results}

The vast majority of respondents felt that children should be able to take part in genomic research testing, whether or not the condition under study began in childhood and independent of 
the existence of known effective treatment (Table 5). We asked if research should be undertaken from a sample collected in childhood but for which the participant (now older than 18 years of age) cannot be located to confirm consent. More than one-third each indicated that they were comfortable using the tissue for the original research purposes $(n=148 / 362,40.9 \%)$ or an expanded purpose $(n=127 / 362,35.1 \%)$. A little more than $40 \%(n=151 / 362)$ thought that the parents should be contacted to ascertain their wishes. Almost none indicated that the tissue should be destroyed $(n=11 / 362,3.0 \%)$. We asked parents

Table 2 Participant attitudes toward unexpected (incidental) findings in genetic research demonstrating that the participant or child has a predisposition to a genetic condition

I would want the UNEXPECTED results of genetic research:

\begin{tabular}{cccc} 
Definitely yes & Maybe yes & Maybe no & Definitely no \\
\hline $\boldsymbol{n}(\%)$ & $\boldsymbol{n}(\%)$ & $\boldsymbol{n}(\%)$ & $\boldsymbol{n}(\%)$ \\
$230(72)$ & $47(15)$ & $19(5)$ & $22(7)$ \\
$280(87)$ & $32(10)$ & $4(1)$ & $5(1)$ \\
$185(58)$ & $79(25)$ & $33(10)$ & $21(7)$ \\
$296(92)$ & $22(7)$ & $3(<1)$ & $1(<1)$ \\
$206(65)$ & $75(24)$ & $23(7)$ & $12(4)$ \\
$249(79)$ & $57(18)$ & $4(1)$ & $7(2)$ \\
\hline
\end{tabular}

Only if the gene explains the condition that I or my family have

That shows a gene that could cause me to die at a younger age for which there is prevention or treatment

That shows a gene that could cause me to die at a younger age for which there is NO prevention or treatment

That shows a gene that could have a health impact for my child, for which there is prevention or treatment

That shows a gene that could have a health impact for my child, for which there is

NO prevention or treatment

That shows a gene that causes a condition with only mild symptoms for my child

$249(79)$

$57(18)$

Table 3 Reasons described by participants to offer genomic research results back to participants

\begin{tabular}{|c|c|c|c|c|c|}
\hline & $\begin{array}{l}\text { Strongly } \\
\text { agree }\end{array}$ & Agree & $\begin{array}{l}\text { Neither agree } \\
\text { nor disagree }\end{array}$ & Disagree & $\begin{array}{l}\text { Strongly } \\
\text { disagree }\end{array}$ \\
\hline The best reasons to give research results back are: & $n(\%)$ & $n(\%)$ & $n(\%)$ & $n(\%)$ & $n(\%)$ \\
\hline $\begin{array}{l}\text { Emphasizes how important the participant was to the research } \\
\text { project }\end{array}$ & $137(44)$ & $109(35)$ & $42(13)$ & $12(4)$ & $12(4)$ \\
\hline $\begin{array}{l}\text { Provides information that may improve the quality of life of the } \\
\text { participant }\end{array}$ & $263(81)$ & $55(17)$ & $5(2)$ & 0 & $2(<1)$ \\
\hline Raises public awareness of the importance of research & $181(54)$ & $108(32)$ & $17(5)$ & $6(2)$ & $5(1)$ \\
\hline Reduces secrecy surrounding research & $131(42)$ & $110(35)$ & $45(15)$ & $12(4)$ & $9(3)$ \\
\hline $\begin{array}{l}\text { Decreases the chance that the participant will feel used by the } \\
\text { researcher }\end{array}$ & $99(33)$ & $93(31)$ & $68(23)$ & $24(8)$ & $18(6)$ \\
\hline
\end{tabular}

Denominator varies per row based on responses to each item.

Table 4 Issues described by respondents for participants/parents to consider in deciding whether or not to receive genomic research results

\begin{tabular}{|c|c|c|c|c|c|}
\hline & $\begin{array}{l}\text { Strongly } \\
\text { agree }\end{array}$ & Agree & $\begin{array}{c}\text { Neither agree } \\
\text { nor disagree }\end{array}$ & Disagree & $\begin{array}{l}\text { Strongly } \\
\text { disagree }\end{array}$ \\
\hline Issues to consider & $n(\%)$ & $n(\%)$ & $n(\%)$ & $n(\%)$ & $n(\%)$ \\
\hline Distress knowing that there is a genetic cause to the condition & $109(35)$ & $118(38)$ & $34(11)$ & $37(12)$ & $10(3)$ \\
\hline $\begin{array}{l}\text { Distress knowing that there are potential problems for other } \\
\text { family members }\end{array}$ & $119(38)$ & $118(38)$ & $31(10)$ & $33(10)$ & $9(3)$ \\
\hline Possible impact upon ability to get insurance in the future & $82(27)$ & $96(31)$ & $70(23)$ & $35(12)$ & $19(6)$ \\
\hline $\begin{array}{l}\text { Possible inaccuracy of the genetic results obtained in a research } \\
\text { context }\end{array}$ & $74(25)$ & $135(46)$ & $72(25)$ & $30(10)$ & $5(2)$ \\
\hline $\begin{array}{l}\text { Possible unnecessary worry about genetic results not likely to } \\
\text { cause harm }\end{array}$ & $67(22)$ & $127(43)$ & $54(18)$ & $43(14)$ & $7(2)$ \\
\hline $\begin{array}{l}\text { Possible danger in misinterpreting the meaning of a genetic result } \\
\text { for a person }\end{array}$ & $75(25)$ & $118(40)$ & $61(21)$ & $38(13)$ & $5(2)$ \\
\hline
\end{tabular}


Table 5 Attitudes of respondents to the question of whether or not children should be allowed to take part in research testing for genetic conditions

\begin{tabular}{|c|c|c|c|c|}
\hline & \multirow{2}{*}{$\begin{array}{c}\text { Strongly agree } \\
n(\%)\end{array}$} & \multirow{2}{*}{$\begin{array}{l}\text { Agree } \\
n(\%)\end{array}$} & \multirow{2}{*}{$\begin{array}{c}\text { Disagree } \\
n(\%)\end{array}$} & \multirow{2}{*}{$\begin{array}{c}\text { Strongly disagree } \\
n(\%)\end{array}$} \\
\hline & & & & \\
\hline $\begin{array}{l}\text { Children should be able to take part in research testing for genetic } \\
\text { conditions that begin during childhood, even if there is no treatment } \\
\text { that can alter the course of the condition }\end{array}$ & $153(48)$ & $140(44)$ & $18(6)$ & $6(2)$ \\
\hline $\begin{array}{l}\text { Children should be able to take part in research testing for genetic } \\
\text { conditions for which there is a treatment that begins during childhood } \\
\text { that can alter the course }\end{array}$ & $216(68)$ & $98(31)$ & 0 & $2(<1)$ \\
\hline $\begin{array}{l}\text { Children should be able to take part in research testing for genetic } \\
\text { conditions that will arise in their adult years, only if there is treatment or } \\
\text { prevention that should begin in childhood }\end{array}$ & $144(46)$ & $105(34)$ & $46(15)$ & $17(5)$ \\
\hline
\end{tabular}

of children with cancer what they would wish if the sample had come from a child who had died in the interim and new genetic research was contemplated. A minority thought the tissue should be used only for original research purposes $(n=18 / 86$, $20.9 \%)$. Almost half felt the tissue should be used for whatever research purpose may be needed $(n=40 / 86,46.5 \%)$ and that parents should be contacted to ask their wishes $(n=42 / 86,48.8$ $\%)$. Again, very few felt that the tissue should not be used for new research purposes $(n=3 / 86,3.5 \%)$.

In the situation in which a child had died, appropriate disposition of the genomic research results was felt to be most often with parents or next of kin $(n=277 / 362,76.5 \%)$. Few indicated that the research results should be published solely in the medical literature $(n=29 / 362,8 \%)$.

\section{Attitudes of participants to the sharing of genomic results with extended family members}

We asked what should occur if genomic research results discovered in their child showed an increased risk of serious health impacts for extended family or relatives. Respondents could choose more than one option. Very few indicated that results should not be shared at all $(n=19 / 362,5.2 \%)$. A minority indicated that the sharing of results should be restricted to exclusively extended family members or relatives that they chose $(n=72 / 362,19.9 \%)$. Almost twice this number would share the result with all extended family at risk $(n=130 / 362,35.9 \%)$. Some indicated that the researcher could share results with kin without their express consent ( $n=64 / 362,17.7 \%)$, and some would require their consent $(n=71 / 362,19.6 \%)$. A minority indicated that this should be done through the physician of the affected individual $(n=68,18.8 \%)$.

We asked respondents to imagine that they had a brother or sister who was found in a research context to have a gene that causes a serious condition for which there was an effective treatment. In this situation, respondents overwhelmingly indicated that they personally had a very strong or strong right ( $n=300 / 323,92.9 \%)$ to be informed of this gene discovery. This remained true even if there was no effective treatment or preventative strategy ( $n=284 / 323,87.9 \%)$. By $\chi^{2}$ analysis, these expressed preferences showed no association with age, ethnicity, education, income, comfort with medical language, or use of the Internet.

\section{Support and process for the return of results}

The majority of participants would recommend that genetic counseling always be offered $(n=139 / 326,42.6 \%)$ or almost always be offered ( $n=41 / 326,12.6 \%)$ before participating in genomic research. Slightly fewer indicated that counseling should always $(n=129 / 326,39.6 \%)$ or almost always $(n=$ $52 / 326,15.9 \%$ ) be offered before providing genomic results. Somewhat surprising, 69 (19.1\%) of the original 362 respondents indicated that they were uncertain what genetic counseling meant.

We probed participants' views of the reliability of genetic results when obtained in a research laboratory versus in a clinical laboratory. Although more than half did not respond (suggesting uncertainty), most who did were of the opinion that a research laboratory was more reliable than a clinical laboratory $(n=70 / 146,47.9 \%)$, or at least as $\operatorname{good}(n=70 / 146,47.9 \%)$. Almost none indicated that a clinical laboratory was more reliable than a research laboratory $(n=6 / 146,4.1 \%)$. Respondent age, education, use of the Internet, or comfort with medical language did not significantly influence this interpretation $\left(\chi^{2}\right.$ analysis).

Participants were asked to consider access to a website on which confidential genetic research results were available describing the potential diseases that one might be at risk for. Respondents indicated that they were likely to access a confidential website to obtain genetic research results about themselves $(n=211 / 281,75.1 \%)$ or their child $(n=220 / 280,78.6 \%)$. By univariate analysis $\left(\chi^{2}\right)$, respondent education, comfort with medical language, comfort using the Internet, and incomebut not age, ethnicity, or severity of underlying disorder-were associated with positively reporting access both for themselves and their child. Multivariate analysis showed the only significant predictor in both cases to be comfort with using the Internet $(P=0.01)$. 


\section{ORIGINAL RESEARCH ARTICLE}

The majority would want access to a list of scientific publications that arose out of the genomic research $(n=246 / 320$, $76.9 \%)$. Most would want a summary of results $(n=305 / 326)$ conveyed variably by a newsletter $(n=127 / 362,35.1 \%)$, a website $(n=118 / 362,32.6 \%)$, yearly information session $(n=$ $51 / 362,14.1 \%)$, or a list of publications $(n=75 / 362,20.7 \%)$.

\section{DISCUSSION}

This study found overall very high expression by respondents of a right to be offered target and incidental genomic results of research in which their child had taken part. We demonstrate, for the first time, that the apparently somatic (cancer) versus germ line nature of the condition under study does not appear to influence this statement.

We found that respondents also hold a different view with respect to genetic research testing in children than that stated in many expert consensus guidelines. ${ }^{27,28}$ Such guidelines typically proscribe testing in childhood unless searching for a condition that can be acted upon in childhood. We found that respondents feel strongly that genomic research should be conducted in children, irrespective of whether the condition is of childhood or adult-onset type or whether there is a known therapeutic intervention. Tercyak et al. ${ }^{14}$ described similar views in the clinical setting. We do not know whether these respondents favoring conduct of genomic research in children considered some of the potential negative impacts (such as loss of longterm autonomy of decision making of the child-the so-called "open future"-or change in family dynamics if the child is found to have a threatening condition). We speculate that parents might be motivated to say yes to genomic results by expectations of information-related benefits or positive benefits for other siblings; for their own health, lifestyle, and reproductive decisions; and in anticipation of future health needs of their children even in the absence of effective treatment.

Our findings are consistent with those of Lakes et al., ${ }^{29}$ who found context to be important to mothers in considering the return of genomic results, including implications for prevention and therapy, personal and familial experience with the disorder, emotional risks, current health status, and flexibility of decision making. Parents reported that many contextual elements are important in considering both the benefits (such as impact on quality of life, prevention of harm, and reduction in secrecy) and the potential harms (such as impact on insurability or work, privacy, ${ }^{8,24}$ limits of analytic accuracy, ${ }^{7}$ and worries about the implications of the newly identified genetic condition). Although most of our respondents indicated that they would want to be notified of results with serious implications, there was an even stronger tendency to want them if remediable by treatment. It will be important to carefully consider with individuals the personal implications if they elect to receive results with no effective therapy. Assisting exploration of these issues - and understanding their health context during the consent process-will be essential in fully informing participants as they consider participation and potential subsequent receipt of genomic results.
FERNANDEZ et al | Participant attitudes toward targeted and incidental genomic findings

Although experts have argued that pediatric genomic research testing and return of results undermines the right of children to decide for themselves, others maintain that receiving genomic results in childhood falls within a parental duty of care to the child. ${ }^{30,31}$ In our study, the majority indicated that they would want results shared with extended family members, either directly or with the assistance of a physician, although they often wanted some control over this sharing. In addition, most would wish genomic research to be shared, even if the child was deceased. Clearly, some parents wish to be engaged with the results and to share them with those who might benefit.

It should be noted that institutional review boards and researchers do not convey such a strong certainty as parents do that genomic research results should be shared, particularly as they relate to incidental or uncertain findings. ${ }^{3,32,33} \mathrm{We}$ have recently found that most researchers advocate that findings related to the target condition be offered to participants in addition to incidental findings of clinical relevance, but they feel much less of an obligation to examine the data they create to uncover incidental significant findings. ${ }^{34}$ Researchers feel even less inclined to share results of uncertain clinical utility, as is typically reflected in guidance policies ${ }^{1,2,35}$ These attitudes are at odds with the parental wishes reflected in our survey. Because there must be a limit to what is reasonably expected of the researcher in the face of expansion of the number of potential disease-associated variants, ${ }^{36}$ clarity about what will or will not be shared should be a focus of discussion at the time of enrollment into the study. ${ }^{37}$

There was a striking faith by our participants in the reliability of research laboratories and a somewhat unexpected finding that a fifth of respondents were uncertain of the function of a genetics counselor. It would appear crucial that limitations of research laboratories, including the absence of Clinical Laboratory Improvements Amendment-type quality assurance, be discussed with participants. For those results that do meet a defined threshold, a robust support system should be in place to facilitate the return of results, including access to and understanding of the role of genetic counselors, in addition to resources to support the enormous process of cataloging and communicating genomic information..$^{38}$ Developing education tools, such as that illustrated by an education and risk communication protocol proposed for use in cancer genetics, will be critical. $^{39}$

The strengths of our study include a unique comparison of views in the context of acquired versus inherited conditions in predominantly pediatric age participants and a national representation of both English and French cohorts. We have a large cross section of parents engaged in genomic research whose views were formed in the context of multiple rare disease types and pediatric brain cancers. In particular, parents of children with orphan diseases bring the perspective of having lived with a familial context to the condition under study. This leads to the reasonable assumption that at least some have had opportunity to reflect on questions related to sharing of health information with extended family. The self-reported ethnic diversity, 
family income, and educational attainment in our respondents are reflective of the Canadian population norms. ${ }^{40}$ Although the sample was consistent with these key population norms, we did not measure other variables (e.g., information-seeking style, trust in medical research) that could potentially affect our findings. Qualitative examination of some of these difficult questions (e.g., whether or not to allow testing for adult-onset genetic conditions that do not need intervention in childhood) could provide more in-depth responses as well as an opportunity to examine how other respondent variables might influence responses. A separate interview study with parents is in press. ${ }^{41}$ It will be important to explore the limits to scenariobased, hypothetical versus actual decision making. We also have incomplete data regarding the short- and longer-term impacts of receiving genomic results and plan a follow-up study for this reason. Finally, survey of parents of children with cancer types other than brain tumors might be instructive.

An argument has been posited by some that the general public does not really understand the implications of asking for incidental findings. The very strong-voiced desire for results by participants engaged in research suggests that researchers will certainly encounter requests for information. Our findings suggest that we must become clearer with what can and should be shared. This discussion can be strengthened by engaging with participants in a frank manner that accounts for the limitations of the information provided, potential burdens on researchers, and/or the opportunity costs of diverting resources from other scientific endeavors.

\section{Conclusion}

We have shown that independent of the context of the underlying orphan disease or cancer or the prospect for direct benefit, respondents express a strong desire to allow genetic research in their children and to receive individual results from this research, a finding consistent with the emerging literature. However, this also points to a lack of congruity between participant attitudes and most expert consensus guidelines. There is a need for better dialogue between researchers and participants at the time of enrollment, study of the impact of honoring the request of parents for detailed and uncertain results, and the creation of guidelines that will uniformly address these issues in an appropriately nuanced and feasible manner. As yet unstudied is how stable these parental opinions are over time-this is also a crucial area to explore as researchers/clinicians engage in the challenge of if, when, and how to offer different types of genomic results to participants.

\section{SUPPLEMENTARY MATERIAL}

Supplementary material is linked to the online version of the paper at http://www.nature.com/gim

\section{ACKNOWLEDGMENTS}

C.V.F. had full access to all the data in the study and takes responsibility for the integrity of the data and the accuracy of the data analysis.
The researchers thank the expert reviewers and parents for the pilot study for validation of the questionnaire. We thank Aleasha Warner (lead research associate, IWK Heath Centre, Halifax, Nova Scotia), Christine Macgillivary (research coordinator, Dalhousie University, Halifax, Nova Scotia), Janet Slaunwhite (database manager, IWK Health Centre, Halifax, Nova Scotia), and the following local site coordinators: Janet Macardier, Children's Hospital of Eastern Ontario, Ottawa, Ontario; Janice Jordaan, Hospital for Sick Children, Toronto, Ontario; Martine Nagy, McGill University, Montreal, Quebec; Barbara Noble, Janeway Hospital, St. John's, Newfoundland; Catherine Desrochers, Health Sciences Center, Winnipeg, Manitoba; and Shelin Adam, BC Clinical Genomics Network, Vancouver, British Columbia, for their superb efforts on this project. We also thank Peter Monette, manager of Bioethics, Science Policy Directorate, Health Canada, for his critical review of the manuscript.

Administrative support was received from Genome Atlantic, Genome British Columbia, and the office of Nancy Hayter, director, Institutional Strategic Initiatives, Dalhousie Research Services, Dalhousie University.

This project was supported by the Canadian Pediatric Cancer Genome Consortium (CPCGC) and the Finding of Rare Genes Canada Consortium (FORGE; both funded by Genome Canada) and the Canadian Institutes of Health Research "Advancing Technology Innovation Through Discovery" program, with additional support from Genome Quebec, Genome British Columbia, and the Ontario Genomics Institute (FORGE; OGI-049).

The Orphan Diseases: Identifying Genes and Novel Therapeutics to Enhance Treatment Project (IGNITE) is funded under the Large Scale Applied Research Program of Genome Canada, with matching funding provided by Health Canada, Departments of Medicine and Ophthalmology, Dalhousie University Faculty of Medicine, the Dalhousie Medical Research Foundation, the Nova Scotia Health Research Foundation, the Dalhousie University Industry and Liaison Office, Genome British Columbia, the Center for Drug Research and Development, Vancouver, British Columbia, the Capital District Health Authority, and the Department of Health and Wellness of Nova Scotia.

None of these funders played a role in the design and conduct of the study; collection, management, analysis, and interpretation of the data; preparation, review, or approval of the manuscript; or decision to submit the manuscript for publication.

Data from this article have been presented in abstract form at the annual meeting of the American Society of Clinical Oncology, Chicago, IL, in June 2013. The work presented in this article is original and has not been previously published in article form.

\section{DISCLOSURE}

The authors declare no conflict of interest.

\section{REFERENCES}

1. Fabsitz RR, McGuire A, Sharp RR, et al. Ethical and practical guidelines for reporting genetic research results to study participants: updated guidelines from a National Heart, Lung, and Blood Institute working group. Circ Cardiovasc Genet 2010;3:574-580.

2. Wolf SM, Crock BN, Van Ness B, et al. Managing incidental findings and research results in genomic research involving biobanks and archived data sets. Genet Med 2012;14:361-384. 
3. Zawati MH, Knoppers BM. International normative perspectives on the return of individual research results and incidental findings in genomic biobanks. Genet Med 2012;14:484-489.

4. Wolf SM, Lawrenz FP, Nelson CA, et al. Managing incidental findings in human subjects research: analysis and recommendations. J Law Med Ethics 2008;36:219-248.

5. Caulfield T, McGuire AL, Cho M, et al. Research ethics recommendations for whole-genome research: consensus statement. PLoS Biol 2008;6:e73.

6. Knoppers BM, Joly Y, Simard J, Durocher F. The emergence of an ethical duty to disclose genetic research results: international perspectives. Eur J Hum Genet 2006:14:1170-1178.

7. Miller FA, Hayeems RZ, Bytautas JP. What is a meaningful result? Disclosing the results of genomic research in autism to research participants. Eur J Hum Genet 2010;18:867-871.

8. Avard D, Silverstein T, Sillon G, Joly Y. Researchers' perceptions of the ethical implications of pharmacogenomics research with children. Public Health Genomics 2009;12:191-201.

9. Knoppers BM. Paediatric research and the communication of not-so incidental findings. Paediatr Child Health 2012;17:190-192.

10. Shalowitz DI, Miller FG. Communicating the results of clinical research to participants: attitudes, practices, and future directions. PLoS Med 2008;5:e91.

11. O'Daniel J, Haga SB. Public perspectives on returning genetics and genomics research results. Public Health Genomics 2011;14:346-355.

12. Tabor HK, Brazg T, Crouch J, et al. Parent perspectives on pediatric genetic research and implications for genotype-driven research recruitment. J Empir Res Hum Res Ethics 2011:6:41-52.

13. Marsh VM, Kamuya DM, Mlamba AM, Williams TN, Molyneux SS Experiences with community engagement and informed consent in a genetic cohort study of severe childhood diseases in Kenya. BMC Med Ethics 2010;11:13

14. Tercyak KP, Hensley Alford S, Emmons KM, Lipkus IM, Wilfond BS, McBride CM. Parents' attitudes toward pediatric genetic testing for common disease risk. Pediatrics 2011;127:e1288-e1295.

15. Madadi P, Joly Y, Avard D, et al. The communication of pharmacogenetic research results: participants weigh in on their informational needs in a pilot study. J Popul Ther Clin Pharmacol 2011;18:e152-e155.

16. Liao SM. Is there a duty to share genetic information? I Med Ethics 2009:35:306-309.

17. Black L, McClellan KA, Avard D, Knoppers BM. Intrafamilial disclosure of risk for hereditary breast and ovarian cancer: points to consider. J Community Genet 2013:4:203-214

18. Canadian Pediatric Genetics Sequencing Consortium. http://www cpgdsconsortium.com/. 2012.

19. Canadian Pediatrics Cancer Genome Consortium. http:// www.bcgsc.ca/ project/the-canadian-pediatric-cancer-genome-consortium-cpcgc. 2012.

20. IGNITE (Orphan Diseases: identifying Genes and Novel Therapeutics to Enhance Treatment). http://igniteproject.ca/orphan_diseases.

21. Cadigan RJ, Michie M, Henderson G, Davis AM, Beskow LM. The meaning of genetic research results: reflections from individuals with and without a known genetic disorder. J Empir Res Hum Res Ethics 2011;6:30-40.

22. Patrick-Miller L, Bradbury AR, Terry MB. Controversies in communication of genetic screening results for cancer: a report from the American Society of Preventive Oncology's Screening Special Interest Group (ASPO's 33rd Annual Meeting, March 8 to 10, 2009, Tampa, Florida). Cancer Epidemiol Biomarkers Prev 2010;19:624-627.
23. Halverson CM, Ross LF. Attitudes of African-American parents about biobank participation and return of results for themselves and their children. J Med Ethics 2012;38:561-566.

24. Kaufman D, Geller G, Leroy L, Murphy J, Scott J, Hudson K. Ethical implications of including children in a large biobank for genetic-epidemiologic research: a qualitative study of public opinion. Am J Med Genet C Semin Med Genet 2008;148C:31-39.

25. van Weely S, Leufkens H. Orphan diseases. In: Priority Medicines for Europe and the World Project "A Public Health Approach to Innovation". http://mednet3. who.int/prioritymeds/report/index.htm. 23 November 2006.

26. Dillman D. Mail and Internet Surveys. The Tailored Design Method, 2nd edn Wiley: New York, 2000.

27. Rao A, Rothman J, Nichols KE. Genetic testing and tumor surveillance for children with cancer predisposition syndromes. Curr Opin Pediatr 2008:20:1-7.

28. American Society of Clinical Oncology. American Society of Clinical Oncology policy statement update: genetic testing for cancer susceptibility. J Clin Oncol 2003;21:2397-2406.

29. Lakes KD, Vaughan $E$, Lemke $A$, et al. Maternal perspectives on the return of genetic results: context matters. Am J Med Genet A 2013;161 A: 38-47.

30. Burke W, Diekema DS. Ethical issues arising from the participation of children in genetic research. J Pediatr 2006;149(suppl):S34-S38.

31. Geller G, Tambor ES, Bernhardt BA, Fraser G, Wissow LS. Informed consent for enrolling minors in genetic susceptibility research: a qualitative study of at-risk children's and parents' views about children's role in decision-making. J Adolesc Health 2003;32:260-271.

32. Simon C, Shinkunas LA, Brandt D, Williams JK. Individual genetic and genomic research results and the tradition of informed consent: exploring US review board guidance. J Med Ethics 2012;38:417-422.

33. Simon CM, Williams JK, Shinkunas L, Brandt D, Daack-Hirsch S, Driessnack M. Informed consent and genomic incidental findings: IRB chair perspectives. J Empir Res Hum Res Ethics 2011;6:53-67.

34. Fernandez CV, Strahlendorf C, Avard D, et al. Attitudes of Canadian researchers toward the return to participants of incidental and targeted genomic findings obtained in a pediatric research setting. Genet Med 2013:15:558-564

35. Meacham MC, Starks H, Burke W, Edwards K. Researcher perspectives on disclosure of incidental findings in genetic research. J Empir Res Hum Res Ethics 2010;5:31-41.

36. Gliwa C, Berkman BE. Do researchers have an obligation to actively look for genetic incidental findings? Am J Bioeth 2013;13:32-42.

37. Cassa CA, Savage SK, Taylor PL, Green RC, McGuire AL, Mandl KD. Disclosing pathogenic genetic variants to research participants: quantifying an emerging ethical responsibility. Genome Res 2012;22:421-428.

38. Kohane IS, Masys DR, Altman RB. The incidentalome: a threat to genomic medicine. JAMA 2006:296:212-215.

39. Roberts JS, Shalowitz DI, Christensen KD, et al. Returning individual research results: development of a cancer genetics education and risk communication protocol. J Empir Res Hum Res Ethics 2011;5:17-30.

40. Government of Canada-National Household Survey 2011. http://www.statcan. gc.ca/sc-rb/rss-eng.html\#a4.

41. Kleiderman E, Knoppers BM, Fernandez C. et al. Returning incidental findings from genetic research to children: views of parents of children affected by rare diseases. J Med Ethics; e-pub ahead of print 19 December 2013. doi:10.1136/ medethics-2013-101648. 